\title{
ACCESSING THE MISSING THIRTY PERCENT OF ENGLISH CHILDREN WHO DON'T SEE A DENTIST
}

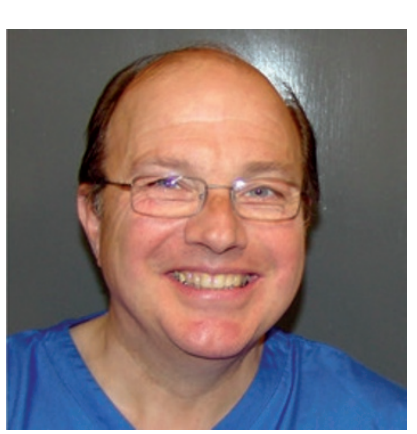

Making sure that the thousands of children every year who don't see a dentist get access to dental care should be a priority for the Government's Mandate to NHS England (NHSE) said British Society of Paediatric Dentistry (BSPD) President Dr Robin Mills, responding to the Department of Health's consultation on the priorities for the years ahead.

A new mandate to NHS England from the Government is due to be published shortly and interested parties were invited to comment on a consultation document. Dr Mills said the general thrust of the document is really good but some opportunities are being missed.

He argues that with improved communication between dentists and opticians and other health professionals, such as GPs, children could be better protected. He would like to see dentists and opticians automatically included in the NHS Spine, just as GPs are. The NHS Spine is a secure database which links hospitals and GPs to patients' NHS numbers. He went on to say that giving dentists a database field within this software would mean they could check a child was linked to a dentist and thus follow up any concerns about the dental status of a child.

He added that dentists and opticians share a unique position within the NHS, in that they are two groups of health professionals who should have regular recall contact with all children and can diagnose serious conditions not always easily detected elsewhere.
Dentists could be helping to care for and protect children as they have a significant role in safeguarding through identifying dental neglect and other child protection issues.

Dr Mills stated: 'Providing a child with easy access to a dental surgeon is a safeguarding requirement and not doing so is a failure to protect a child.' He also said that in areas where accessing a dental care service for children is difficult, the salaried dental services should be mandated to pick up these 'missing' children.

There is quite rightly a focus in the consultation on the aging population, said Dr Mills, adding: 'but getting it right for children in oral health is known to have a beneficial effect later in life with low maintenance and low cost outcomes for the NHS.'

The NHS could also be saving money by addressing the shortage of specialist paediatric dentists, he argued. Transformation of 'out-ofhospital' care is a priority for the Department of Health and this is a reasonable objective as hospital care is expensive.

There are exceptions, however, and Dr Mills observed that general anaesthetics for extraction of teeth in children can only take place in a hospital setting as this has been shown to be the safest and most appropriate environment. This is costing the NHS $£ 30$ million annually in England alone.

He continued: 'The shortage of paediatric specialists to carry out treatment planning for this service is not only more likely to lead to more repeat anaesthesia but may leave a legacy of more complex treatment requirements in later life. A substantial reduction in this $£ 30$ million could be achieved by more specialist care.'

He suggests that there should be a network of specialist centres for treatment of children and planning of their care under general anaesthesia in the existing District General Hospital infrastructure together with a better distribution of specialists around the country.

BSPD would also like to see a preventive programme introduced in England like the successful Childsmile in Scotland which would ultimately reduce the unacceptable number of children requiring dental treatment under general anaesthesia in England.

'It cannot be emphasised enough that a programme such as this, utilising early and effective prevention has the potential to significantly save on both child and adult treatment costs.'

\section{CONFERENCE ROUND-UP BELFAST HOSTS INTERNATIONAL RESTORATIVE DENTISTRY CONFERENCE}

In October, almost 300 delegates arrived in Belfast to attend the joint meeting of the European College of Gerodontology (ECG), the Specialist Registrars in

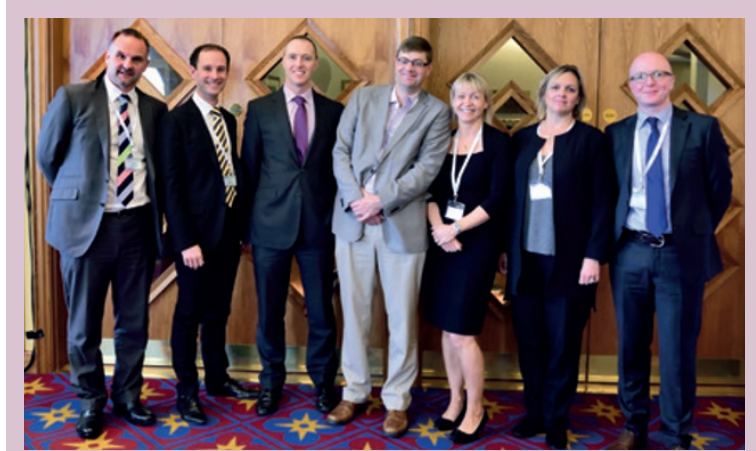

Oncology discussion panel members: L-R Prof. Craig Barclay, Dr Simon Critchlow, Dr John Hanratty, Dr Chris Butterworth, Dr Lorna McCall, Dr Clare Morgan, Dr Simon Killough.
Restorative Dentistry Group (SRRDG) and the Association of Consultants and Specialists in Restorative Dentistry (RD-UK). Held in the impressive surrounds of Titanic Belfast, the theme of the meeting was 'Restorative Dentistry for all Generations'. The two day event featured hands-on practical sessions covering digital treatment planning and endodontic retreatment led by Dr Hal Duncan (Trinity College Dublin) and Dr Luc Van der Luiss (University of Groningen, the Netherlands). One of the highlights of the meeting was a panel discussion on the management of head and neck oncology chaired by Dr Simon Critchlow,
(Royal London Hospital, chair of SRRDG) and featuring contributions from Professor Craig Barclay (University of Manchester), Dr Simon Killough (Queens University Belfast), and Dr John Hanratty (Altnagelvin Area Hospital, Derry).

The meeting featured a list of impressive local and international speakers including Professor Jimmy Steele (University of Newcastle), Professor Frauke Muller (University of Geneva), Professor Finbarr Allen (University College Cork), Dr Gerry McKenna (ECG President, Queens University Belfast) and Professor Chris Irwin (Queens University Belfast). 